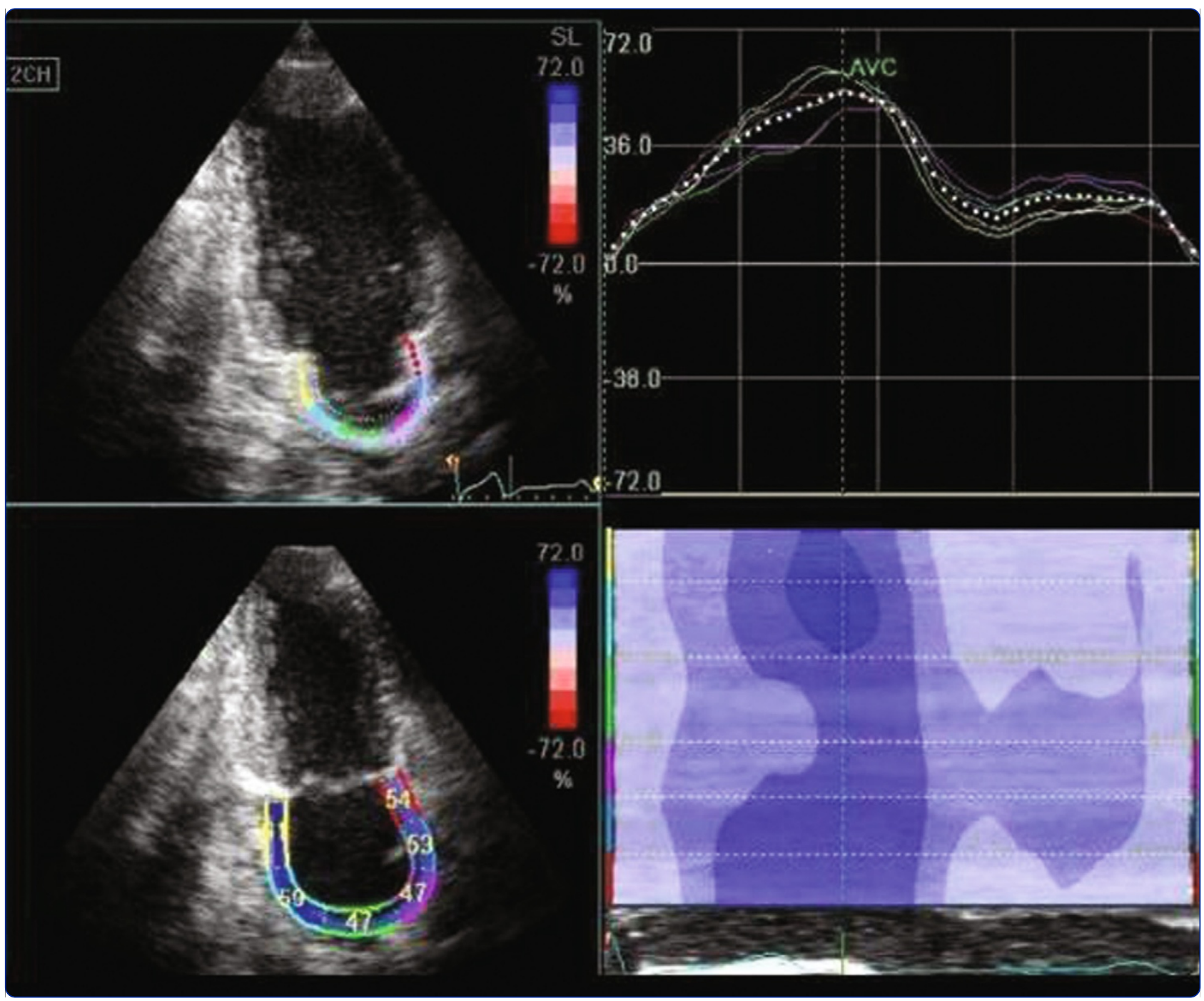

Speckle echocardiographic left atrial strain and stiffness index as predictors of maintenance of sinus rhythm after cardioversion for atrial fibrillation: a prospective study

Shaikh et al. 


\title{
Speckle echocardiographic left atrial strain and stiffness index as predictors of maintenance of sinus rhythm after cardioversion for atrial fibrillation: a prospective study
}

Amir Y Shaikh ${ }^{1 \dagger}$, Abhishek Maan ${ }^{1 \dagger}$, Umar A Khan ${ }^{1 \dagger}$, Gerard P Aurigemma ${ }^{2 \dagger}$, Jeffrey C Hill ${ }^{3 \dagger}$, Jennifer L Kane ${ }^{2 \dagger}$, Dennis A Tighe ${ }^{2 \dagger}$, Eric Mick ${ }^{4 \dagger}$ and David D McManus ${ }^{2,5^{*}+}$

\begin{abstract}
Background: Echocardiographic left atrial (LA) strain parameters have been associated with atrial fibrillation (AF) in prior studies. Our goal was to determine if strain measures [peak systolic longitudinal strain (LAS) and stiffness index (LASt)] changed after cardioversion (CV); and their relation to AF recurrence.

Methods and results: 46 participants with persistent AF and 41 age-matched participants with no AF were recruited. LAS and LASt were measured before and immediately after CV using 2D speckle tracking imaging (2DSI). Maintenance of sinus rhythm was assessed over a 6-month follow up. Mean LAS was lower, and mean LASt higher, in participants with AF before CV as compared to control group (11.9 \pm 1.0 vs $35.7 \pm 1.7, p<0.01$ and $1.31 \pm 0.17$ vs $0.23 \pm 0.01, p<0.01$, respectively). There was an increase in the mean LAS immediately after CV (11.9 \pm 1.0 vs $15.9 \pm 1.3$, $p<0.01)$, whereas mean LASt did not change significantly after $C V(p=0.62)$. Although neither LAS nor LASt were independently associated with AF recurrence during the follow-up period, change in LAS after cardioversion (post-CV LAS - pre-CV LAS) was significantly higher among individuals who remained in sinus rhythm when compared to individuals with recurrent AF (3.6 \pm 1.1 vs $0.4 \pm 0.8, p=0.02)$.

Conclusions: LAS and LASt differed between participants with and without AF, irrespective of the rhythm at the time of echocardiographic assessment. Baseline LAS and LASt were not associated with AF recurrence. However, change in LAS after CV may be a useful predictor of recurrent arrhythmia.
\end{abstract}

Keywords: Arrhythmia, Echocardiography, Strain, Stiffness

\section{Introduction}

Atrial fibrillation (AF) is the most common arrhythmia encountered, and the population burden of $\mathrm{AF}$ is increasing [1-7]. Pathological atrial structural remodeling characterized, by fibrosis and myofiber disarray, plays a critical role in AF initiation and maintenance [1,8-10].

\footnotetext{
* Correspondence: mcmanusd@ummhc.org

${ }^{\dagger}$ Equal contributors

${ }^{2}$ Division of Cardiovascular Medicine, University of Massachusetts Medical School, Worcester, USA

${ }^{5}$ Department of Medicine, Cardiology Division, Electrophysiology Section, University of Massachusetts Medical Center, 55 Lake Avenue North,

Worcester, MA 01655, USA

Full list of author information is available at the end of the article
}

Increased left atrial (LA) size on echocardiogram is associated with incident $\mathrm{AF}$, recurrent $\mathrm{AF}$, stroke and mortality [4,11-15]. Nevertheless, LA size only slightly improves AF risk prediction [16]. More recently, atrial myocardial deformation properties measured as strain, strain rate and stiffness (E/E'/strain) by tissue Doppler Imaging (TDI) and 2D speckle tracking imaging (2DSI) have shown promise as markers of atrial structural remodeling and as predictors of AF [1-5,17-19]. 2DSI measures local atrial myocardial deformation and unlike TDI, is angle independent, and unaffected by cardiac translation or tethering effect $[4,15]$.

Preliminary work suggests that LA strain parameters are independent predictors of recurrence of $\mathrm{AF}$ in subjects

\section{Biomed Central}

(c) 2012 Shaikh et al.; licensee BioMed Central Ltd. This is an Open Access article distributed under the terms of the Creative Commons Attribution License (http://creativecommons.org/licenses/by/2.0), which permits unrestricted use, distribution, and reproduction in any medium, provided the original work is properly cited. 
undergoing cardioversion (CV) or catheter ablation $[6,9,20-22]$. The purpose of this prospective investigation was to determine if LA stiffness index (LASt), and/or peak systolic longitudinal LA strain (LAS) changed after $\mathrm{CV}$ in subjects with persistent AF; and their relation as predictors of maintenance of sinus rhythm. To our knowledge, this is the first study evaluating the role of LASt in AF recurrence after CV.

\section{Methods}

\section{Patient population}

This study was approved by the University of Massachusetts Medical School Institutional Review Board. Between June of 2010 and May of 2011, 46 participants with persistent AF (duration of less than 12 months) undergoing a clinically indicated elective CV for AF and 41 age-matched controls were recruited. Written-informed consent was obtained prior to enrollment. Exclusion criteria were: history of prior cardiac surgery, history of atrial flutter, history of paced atrial or ventricular rhythm, history of aortic or mitral valvular prosthesis, history of significant (moderate or greater) mitral insufficiency or stenosis, history of atrial or ventricular thrombus, history of atrial septal defect, pregnancy, age less than 18 , inability to give consent and failure of $\mathrm{CV}$. Five participants were excluded from the study since they failed cardioversion. Control subjects were subjects who had undergone an echocardiogram for varied indications but had no history of AF. A standard 2-Dimensional (2D) transthoracic echocardiography (TTE) was performed prior to elective $\mathrm{CV}$ and was repeated within $24 \mathrm{~h}$ post-CV in sinus rhythm. CV was performed as per ACC/AHA/ESC guidelines with direct-current, synchronized shock in fasting subjects after intravenous sedation [23].

\section{Echocardiography}

A standard TTE was performed using a Vivid 7 (GE Healthcare, Waukesha, WI) and a $1.7 / 3.4 \mathrm{MHz}$ tissue harmonic transducer with a frame rate of at least 50 frames per second. Machine settings were manually adjusted to optimize 2D endocardial and myocardial gray scale definition. Care was taken to obtain true apical images using standard anatomic landmarks in each view and not foreshorten the left ventricle or left atrium. All images were acquired at end-expiratory apnea. Loops of 5 cardiac cycles were stored digitally and analyzed offline using a customized software package (EchoPAC, GE Healthcare).

\section{Two-dimensional and Doppler echocardiographic variables}

LA diameter (LAD) was measured at end-systole along the parasternal long-axis view. Maximum LA volume (end-ventricular systole) was calculated from apical 4and apical 2-chamber views of the LA using the biplane method of disks, as is recommended by the American Society of Echocardiography [24]. Left ventricular endsystolic volume, left ventricular end-diastolic volume, and left ventricular ejection fraction (LVEF) were measured. Mitral flow velocity (E) was assessed by pulsedwave Doppler from the apical 4 chamber view by placing a sample volume between the tips of the mitral leaflets in diastole and recording at a sweep speed of $100 \mathrm{~mm} / \mathrm{s}$. Peak flow velocities were measured and averaged from five consecutive cycles. The average of lateral and medial mitral annulus early diastolic velocity (E') was measured using TDI. The E/E' ratio was used to estimate filling pressures [25].

\section{Speckle tracking imaging}

Offline 2DSI technique was used to calculate LAS in individual LA regions. For 2DSI, a line was manually drawn along the LA endocardium at peak systole corresponding with the aortic valve closure. The software then automatically generated additional lines near the atrial epicardium, with a region of interest default width that was manually adjusted. Before processing, a cine loop preview feature was utilized to visually confirm that the internal line follows the LA endocardium throughout the cardiac cycle. If tracking of the LA endocardium was found to be unsatisfactory, then manual adjustments or changing software parameters (e.g., region of interest size or smoothing functions) were made. For analysis of the LAS, region of interest was divided into 6 segments of the LA wall in each 4 and 2 chamber views and were manually tracked frame by frame to maintain the position within the LA wall. LAS was measured at each segment divided from the annulus to the roof of LA (Figure 1). The LAS of the 6 segments was averaged for analysis. Approximately $90.5 \%$ of the individual segments throughout the study had adequate speckle tracking, and were included for strain analysis. The other $9.5 \%$ of the individual segments had inadequate speckle tracking due to either poor image quality or pulmonary vein openings, and were excluded from the analysis. Inter-observer variability expressed as a coefficient of variation, was assessed by analyzing 10 randomly chosen subjects by 2 independent investigators. For intra-observer variability, 10 randomly chosen participants were analyzed by the same investigator twice with a minimum gap of a month. The intra-observer and inter-observer variability for LAS were $4 \%$ and $7 \%$ respectively, and for LASt were $5 \%$ and $7 \%$ respectively.

In a recent study the validity and accuracy of LASt was examined using both invasive LA pressure, and non-invasive surrogates of left atrial pressure $(\mathrm{E} / \mathrm{A}, \mathrm{E} / \mathrm{E}$, and $\left.E / V_{p}\right)[21]$. The calculation of LASt using $E / E$ ' had closest correlation to LASt derived by invasive LA pressures [21]. In our study we calculated the LASt as (E/E'/LAS). 


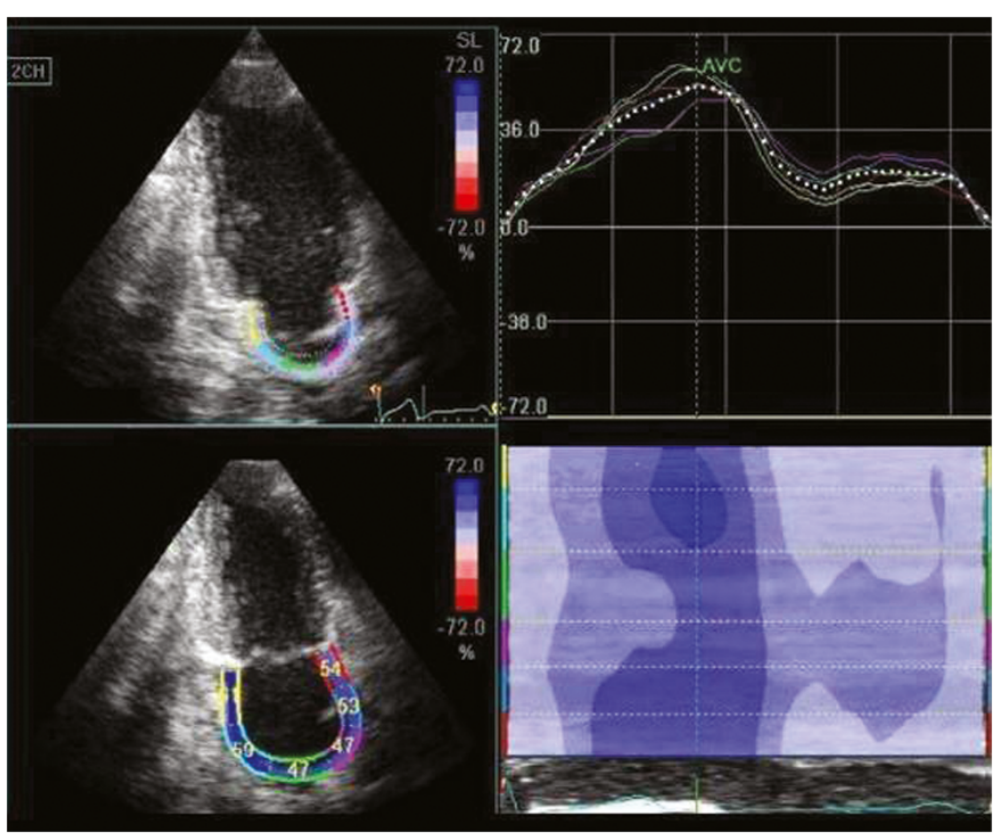

Figure 1 Assessment of peak systolic longitudinal left atrial strain (LAS) by 2D speckle tracking imaging (2DSI).

\section{Atrial fibrillation}

AF at baseline was diagnosed on a 12-lead electrocardiogram. All participants were discharged with a 30-day continuous electrocardiography recording monitor (Heartrak ECAT(External Cardiac Ambulatory Telemetry); AMI Cardiac Monitoring; Sandy Spring, Maryland) after CV. Any abnormal electrical activity recordings were transmitted to the electrophysiologist on a daily basis even if not triggered by subjects and asymptomatic. All AF recurrences were adjudicated by an experienced cardiac electrophysiologist (DDM). Using an electronic medical record chart review, subjects were followed for 6 months for interim hospitalizations, emergency room visits and outpatient visits. Any evidence of AF based on electrocardiographic findings was considered as recurrence.

\section{Statistical analysis}

The data were initially analyzed for normality. Chi square tests for categorical variables and Student's $t$ test for continuous variables were used to examine potential differences between study groups. Wilcoxon rank sum test for paired variables and Mann-Whitney $U$ test for unpaired variables were used for data that did not have a normal distribution. Ordinal variables were tabulated as mean \pm 2 SEM or with the confidence intervals of $5^{\text {th }}$ and $95^{\text {th }}$ percentiles.

Area under the Receiver Operating Curve (ROC), univariate and multivariate analysis were performed to describe the prognostic value of strain parameters for prediction of sinus rhythm maintenance after CV. Cutoff for $\mathrm{p}$ values in univariate analysis was 0.3 to enter multivariate analysis; and was considered statistically significant in multivariate analysis only if $\mathrm{p}$ was $<0.05$. Sensitivity, specificity and optimal cut-off values were determined from the ROC curve data. All the analyses were performed with commercially available packages for (SPSS, Version 20.0, SPSS Inc., Chicago, IL, USA; and GraphPad Prism version 5.00 for Windows, GraphPad Software, San Diego, California, USA).

\section{Results}

\section{Clinical characteristics of AF and controls}

The general clinical characteristics are recorded in Table 1. Subjects in AF group were predominantly male, and had a higher incidence of obesity, hypertension and heart failure as compared to the control group.

\section{Comparison of echocardiographic and strain parameters in AF and controls pre and post CV}

The echocardiographic variables and strain parameters in participants with AF and controls with no history of AF are displayed in Table 2. Mean LAS was significantly lower in subjects with $\mathrm{AF}$, pre- $\mathrm{CV}$ as compared to the control group $(11.9 \pm 1.0$ vs $35.7 \pm 1.7, \mathrm{p}<0.01)$ (Figure 2$)$. Mean LAS was lower $(15.9 \pm 1.3$ vs $35.7 \pm 1.7, \mathrm{p}<0.01)$, and mean LASt higher $(1.1 \pm 0.3$ vs $0.2 \pm 0.01, \mathrm{p}<0.01)$, in participants with AF after CV as compared to participants with no history of AF (Figure 2). Among participants with $\mathrm{AF}$, there was a significant increase in mean LAS (11.9 \pm 1.0 vs $15.9 \pm 1.3, \mathrm{p}<0.01)$, but no change in LASt $(\mathrm{p}=0.62)$, after CV (Figure 3). 
Table 1 Baseline clinical characteristics of patients with atrial fibrillation (AF) as compared to the control group

\begin{tabular}{|c|c|c|c|}
\hline & $A F(41) n(\%)$ & Controls (41) n (\%) & $P$ value \\
\hline Mean age (years) & $64.5 \pm 4.0$ & $61.7 \pm 2.4$ & 0.12 \\
\hline $\operatorname{Sex}(M / F)$ & 29/12 & $13 / 28$ & $<0.01$ \\
\hline BMI $\left(\mathrm{Kg} / \mathrm{m}^{2}\right)$ & $32.5 \pm 2.3$ & $25.8 \pm 1.6$ & $<0.01$ \\
\hline \multicolumn{4}{|l|}{ Comorbid conditions: } \\
\hline HTN & $30(73.2)$ & $16(39)$ & $<0.01$ \\
\hline CAD & $14(34.1)$ & $4(9.7)$ & $<0.01$ \\
\hline Systolic HF & $13(31.7)$ & 0 & $<0.01$ \\
\hline CVA & $1(2.4)$ & 0 & 1.0 \\
\hline $\mathrm{DM}$ & $11(26.8)$ & $4(9.7)$ & 0.08 \\
\hline Dyslipidemia & $24(58.5)$ & $9(21.9)$ & $<0.01$ \\
\hline \multicolumn{4}{|l|}{ Medications: } \\
\hline Statins & $22(53.6)$ & $6(14.6)$ & $<0.01$ \\
\hline Beta blockers & $27(65.8)$ & $9(21.9)$ & $<0.01$ \\
\hline ACE-i/ARB & $24(58.5)$ & $8(19.5)$ & $<0.01$ \\
\hline$C C B$ & $17(41.5)$ & $5(12.2)$ & $<0.01$ \\
\hline Digoxin & $4(9.7)$ & 0 & 0.11 \\
\hline Diuretics & $21(51.2)$ & $5(12.2)$ & $<0.01$ \\
\hline ASA & $30(73.2)$ & $5(12.2)$ & $<0.01$ \\
\hline Clopidogrel & $2(4.8)$ & 0 & 0.49 \\
\hline Warfarin & $28(68.3)$ & $3(7.3)$ & $<0.01$ \\
\hline Heparin & $4(9.7)$ & 0 & 0.11 \\
\hline Amiodarone & $8(19.5)$ & 0 & $<0.01$ \\
\hline Sotalol & $5(12.2)$ & 0 & 0.05 \\
\hline Other anti-arrhythmics & $4(9.7)$ & 0 & 0.11 \\
\hline
\end{tabular}

BMI - Body Mass Index, HTN - Hypertension, CAD - Coronary artery disease, HF- Heart failure, DM - Diabetes Mellitus, CVA - Cerebrovascular accident, ACE-i/ARB - Angiotensinogen converting enzyme inhibitors/Angiotensin receptor blockers, CCB - Calcium channel blockers, ASA - Aspirin.

\section{Clinical characteristics of the maintained sinus rhythm (MSR) and AF recurrence (AFR) groups}

Twenty-seven (66\%) of participants undergoing CV for persistent AF remained in normal sinus rhythm throughout the 6-month follow-up period, whereas 14 (34\%) experienced at least 1 recurrence of AF. There was no significant difference in age, sex, body mass index (BMI), comorbidities or medications, especially anti-arrhythmic drugs between both the groups (Table 3). Three out of fourteen subjects had AF recurrence within $24 \mathrm{~h}$. Eight out of fourteen subjects had AF recurrence within 30 days. The remaining three subjects had AF recurrence between one and six months. Amongst the subjects who had a recurrence within 30 days, the mean AF burden was $46.13 \%$. None of the study subjects had new onset stroke or transient ischemic attack during the 6 month follow up.
Comparison of echocardiographic and strain parameters in the MSR and AFR group

The echocardiographic variables and strain parameters of MSR and AFR groups are recorded in Table 4. There was no significant difference in mean pre-CV LAS between both the groups $(11.8 \pm 1.3$ vs $12.0 \pm 1.6$, $\mathrm{p}=0.95)$. Mean post-CV LAS was higher in the MSR group as compared to the AFR group (17.0 \pm 1.8 vs $13.5 \pm$ 1.7, $\mathrm{p}=0.19)$. In the MSR group, mean LAS after CV was higher as compared to the pre-CV LAS $(11.8 \pm 1.3$ vs $17.0 \pm$ $1.8, \mathrm{p}<0.01)$. In contradistinction, participants who had a recurrence of AF had no significant change in LAS after CV $(12.0 \pm 1.6$ vs $13.5 \pm 1.7, \mathrm{p}=0.38)$ (Figure 4). Difference in mean LAS after CV was statistically significant in the MSR group as compared to the AFR group ( $3.6 \pm 1.1$ vs $0.4 \pm 0.8$, $\mathrm{p}=0.02$ ). There was no significant change in mean LASt after CV in either the MSR or the AFR group $(1.28 \pm 0.22$ vs $1.12 \pm 0.41, \mathrm{p}=0.92 ; 1.38 \pm 0.26$ vs $0.87 \pm 0.18 ; \mathrm{p}=0.22$ ) respectively.

\section{LAS and LASt as predictors for maintenance of sinus rhythm}

A regression analysis adjusted for age, sex and BMI was performed initially and showed that difference in strain (post-CV LAS - pre-CV LAS) was a predictor of maintenance of sinus rhythm (B coefficient 3.1, $\mathrm{p}=0.09$ ). Further multivariate regression adjusting for age and BMI, demonstrated that the difference in strain showed a trend towards prediction of MSR (B coefficient 3.7, $\mathrm{p}=0.08$ ) (Table 5). ROC curves were plotted for pre-CV LAS (AUC $0.52 \pm 0.09$ ), post-CV LAS (AUC $0.38 \pm 0.09$ ) and difference in strain (AUC $0.38 \pm 0.09$ ). ROC curves for pre-CV LASt had an AUC of $0.43 \pm 0.08$.

\section{Discussion}

In this prospective clinical study involving 82 participants, we found that mean LAS was lower and mean LASt higher in subjects with AF as compared to those in normal sinus rhythm and no history of AF. We also observed that, although mean LAS improved immediately after CV in subjects with AF, it failed to normalize completely and remained lower in subjects with a history of AF than the control group. Mean LASt did not significantly change after CV. Compared with individuals who experienced a recurrence of AF over the follow-up period, those who remained in normal sinus rhythm were more likely to experience a significant improvement in the LAS after $\mathrm{CV}$. Difference in strain (post-CV LAS - pre-CV LAS) showed a trend towards prediction of maintenance of sinus rhythm after cardioversion.

\section{Atrial myocardial deformation properties and AF}

Normal LA function comprises three components: reservoir function, serving to store blood from the pulmonary 
Table 2 Echocardiographic and strain variables of patients with atrial fibrillation (AF) as compared to the control group

\begin{tabular}{|c|c|c|c|c|c|}
\hline Echo variables & $A F(n=41)$ & & & Controls $(n=41)$ & $P$ value \\
\hline LVIDd, mm & $50.2 \pm 2.6$ & & & $44.8 \pm 1.8$ & $<0.01$ \\
\hline LVIDs, mm & $35.6 \pm 3.2$ & & & $28.0 \pm 1.8$ & $<0.01$ \\
\hline $\mathrm{STd}, \mathrm{mm}$ & $10 \pm 0.6$ & & & $8.9 \pm 0.6$ & $<0.01$ \\
\hline PWTd, mm & $10 \pm 0.6$ & & & $8.1 \pm 0.6$ & $<0.01$ \\
\hline LVEF (\%) & $54.0 \pm 3.6$ & & & $65.1 \pm 1.0$ & $<0.01$ \\
\hline$L A D, m m$ & $45.9 \pm 4.0$ & & & $33.4 \pm 2.0$ & $<0.01$ \\
\hline $\mathrm{LAVI}, \mathrm{ml} / \mathrm{M}^{2}$ & $34.7 \pm 4.0$ & & & $23.4 \pm 3.2$ & $<0.01$ \\
\hline \multirow[t]{2}{*}{$E / E^{\prime}$} & $10.7 \pm 1.8$ & & & $7.6 \pm 0.8$ & $<0.01$ \\
\hline & Pre- CV & Post- CV & $P$ value & & \\
\hline $2 \mathrm{CLAS}, \%$ & $12.7(10.2-15.2)$ & $16.5(13.2-19.9)$ & 0.01 & $38.3(33.1-43.5)$ & $<0.01$ \\
\hline $4 C L A S, \%$ & $11.0(8.6-13.5)$ & $15.2(12.4-18.0)$ & $<0.01$ & $33.1(29.6-36.6)$ & $<0.01$ \\
\hline LAS, \% & $11.9(9.8-13.9)$ & $15.9(13.1-18.7)$ & $<0.01$ & $35.7(32.1-39.3)$ & $<0.01$ \\
\hline 2CLASt & $1.06(0.81-1.32)$ & $1.25(0.16-2.33)$ & 0.67 & $0.24(0.19-0.28)$ & $<0.01$ \\
\hline 4CLASt & $1.57(1.04-2.10)$ & $0.85(0.61-1.09)$ & 0.02 & $0.24(0.20-0.28)$ & $<0.01$ \\
\hline LASt & $1.32(0.97-1.67)$ & $1.05(0.44-1.66)$ & 0.62 & $0.23(0.19-0.27)$ & $<0.01$ \\
\hline
\end{tabular}

LVIDd - Left ventricular internal diameter at end- diastole, LVIDs - Left ventricular internal diameter at end- systole, STd - Interventricular septum thickness at end-diastole, PWTd - Left ventricular posterior wall thickness at end-diastole, LVEF - Left ventricular ejection fraction, LAD - Left atrial diameter, LAVI - Left atrial volume index, $\mathrm{E}=$ early filling velocity of transmitral Doppler flow, $\mathrm{E}^{\prime}=$ Average early diastolic velocity of medial and lateral mitral annulus, $2 \mathrm{CLAS}-2$ chamber average peak systolic strain, 4CLAS - 4 chamber average peak systolic strain, LAS - Mean peak systolic strain of 2 C and $4 C, 2 C L A S t-2$ chamber left atrial stiffness, $4 C L A S t-4$ chamber left atrial stiffness, LASt - Mean left atrial stiffness of $2 \mathrm{C}$ and $4 \mathrm{C}$.

veins; conduit function, wherein blood passes through the left atrium from the pulmonary veins to the left ventricle in early diastole; and booster function, where atrial contraction serves to increase end diastolic ventricular fiber stretch [2]. Several studies have demonstrated that atrial structural remodeling during $\mathrm{AF}$ is due to a variable degree of fibrosis, atrial myocyte hypertrophy, myofiber disarray and apoptosis $[8,10]$. Atrial strain parameters have been proven to correlate significantly with the underlying fibrosis and have been validated against sonomicrometry and tagged MRI, thus providing a comprehensive real time quantitative assessment of regional atrial myocardial deformation $[15,26]$. However, strain and strain rate can be influenced by loading conditions and may be influenced by rhythm irregularity, irrespective of degree of underlying fibrosis [3,9].
Preliminary work suggests that LA strain parameters are independent predictors of recurrence of AF in subjects undergoing cardioversion $(\mathrm{CV})$ or catheter ablation $[6,9,20-22]$. Accordingly, the study was undertaken to better understand to what extent systolic strain is influenced by the atrial rhythm. We also evaluated the role of these strain variables in predicting the recurrence of AF.

\section{Recovery of left atrial function after CV and re-established} sinus rhythm

Our finding that LAS was significantly lower in subjects with $\mathrm{AF}$ as compared to controls was similar to the findings of prior studies $[3,4,6,22]$. As has previously been reported in the published literature, LAS increased significantly immediately after CV. However, mean LAS did not normalize completely $[6,7,27,28]$. This is consistent with
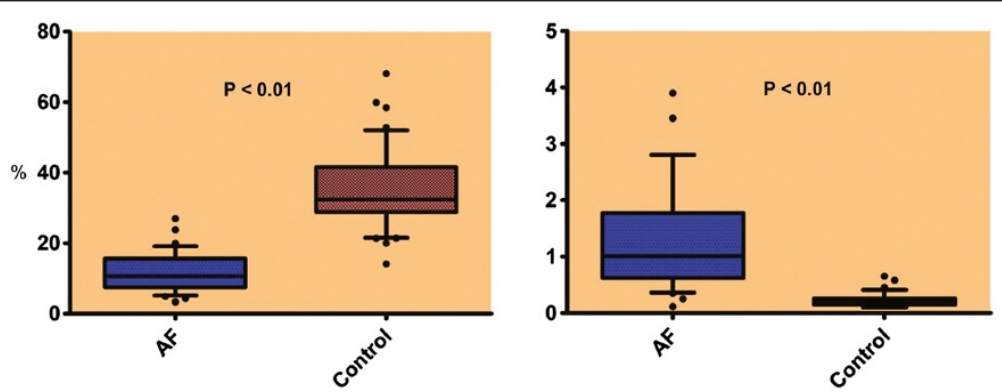

Figure 2 Comparison of mean LAS (left) and of left atrial stiffness index (LASt) (right) at baseline between the AF group and control group. 

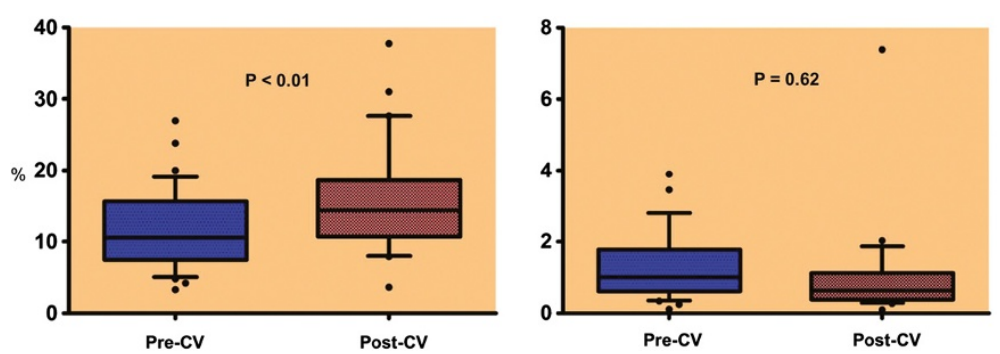

Figure 3 Comparison of mean LAS (left panel) and of LASt (right panel) in subjects with AF pre and post cardioversion (CV).

the findings of a 3-year follow-up study, which demonstrated that although the LA contractility improved after successful CV, it remained modestly impaired [27]. In contrast to this work, however, we measured LAS immediately after CV instead of 1 month after CV. The improvement in LA strain after CV or catheter ablation has been previously

Table 3 Baseline clinical characteristics of patients in the maintained sinus rhythm (MSR) group as compared to the atrial fibrillation recurrence (AFR) group

\begin{tabular}{|c|c|c|c|}
\hline & MSR (27) n (\%) & AFR (14) n (\%) & $P$ value \\
\hline Mean age (years) & $65 \pm 5.0$ & $64 \pm 6.8$ & 0.9 \\
\hline $\operatorname{Sex}(M / F)$ & $21 / 6$ & $8 / 6$ & 0.28 \\
\hline $\mathrm{BMI}\left(\mathrm{Kg} / \mathrm{m}^{2}\right)$ & $32 \pm 3.0$ & $34 \pm 3.6$ & 0.26 \\
\hline \multicolumn{4}{|l|}{ Comorbid conditions: } \\
\hline HTN & $21(77.8)$ & $12(85.7)$ & 0.69 \\
\hline$C A D$ & $9(33.3)$ & $5(35.7)$ & 1.0 \\
\hline Systolic HF & $11(40.7)$ & $3(21.4)$ & 0.3 \\
\hline CVA & $0(0)$ & $1(7.1)$ & 0.34 \\
\hline DM & $5(18.5)$ & $6(42.8)$ & 0.14 \\
\hline Dyslipidemia & $16(59.2)$ & $8(57.1)$ & 1.0 \\
\hline \multicolumn{4}{|l|}{ Medications: } \\
\hline Statins & $14(51.8)$ & $8(57.1)$ & 1.0 \\
\hline Beta blockers & $20(74.1)$ & $7(50.0)$ & 0.17 \\
\hline ACE-i/ARB & $14(51.8)$ & $11(78.5)$ & 0.17 \\
\hline CCB & $12(44.5)$ & $6(42.8)$ & 1.0 \\
\hline Digoxin & $2(7.4)$ & $2(14.3)$ & 0.59 \\
\hline Diuretics & $16(59.2)$ & $5(35.7)$ & 0.19 \\
\hline ASA & $18(66.7)$ & $12(85.7)$ & 0.28 \\
\hline Clopidogrel & $1(3.7)$ & $1(7.1)$ & 1.0 \\
\hline Warfarin & $18(66.7)$ & $10(71.4)$ & 1.0 \\
\hline Heparin & $1(3.7)$ & $3(21.4)$ & 0.11 \\
\hline Amiodarone & $7(25.9)$ & $1(7.1)$ & 0.23 \\
\hline Sotalol & $2(7.4)$ & $3(21.4)$ & 0.32 \\
\hline Other anti-arrhythmics & $3(11.1)$ & $1(7.1)$ & 1.0 \\
\hline
\end{tabular}

BMI - Body Mass Index, HTN - Hypertension, CAD - Coronary artery disease, HF- Heart failure, DM - Diabetes Mellitus, CVA - Cerebrovascular accident, ACE-i/ARB - Angiotensinogen converting enzyme inhibitors/Angiotensin receptor blockers, CCB - Calcium channel blockers, ASA - Aspirin. attributed to 'reverse atrial remodeling [27]. The immediate improvement in LAS after cardioversion in individuals with AF enrolled in our study makes structural remodeling less likely and restoration of atrial contraction as the more likely cause of the change in LAS. The fact that LAS measured immediately after CV did not improve to levels seen among individuals with no history of AF could have resulted from "atrial stunning" or from persistent mechanical and/or LA structural abnormalities.

As has been previously reported [21], baseline LASt was significantly higher among participants with AF as compared to participants with no AF, likely secondary to decreased LA compliance in subjects with AF. Interestingly, there was no change in LASt immediately after CV. In comparison with LAS, the fact that LASt values were similar in AF and after cardioversion in sinus rhythm, suggests that LASt is a more reliable index of the underlying structural characteristics of the LA than LAS. Stiffness being directly proportional to LA size, it is not surprising that LASt did not change in the short term, as there was no opportunity for reverse remodeling of the LA.

\section{Prediction of maintenance of sinus rhythm}

The degree of impairment in atrial compliance, as assessed by LAS, has been reported to relate to maintenance of sinus rhythm after $\mathrm{CV}$ or catheter ablation in subjects with persistent AF [2,3,6,9]. However, our study findings showed no significant difference for the preand post-CV LAS and LASt values between the MSR and AFR group. Also unlike prior studies, we did not find baseline LAS or LASt to be an independent predictor of maintenance of sinus rhythm [21]. We found that the change in LAS was associated with maintenance of sinus rhythm. Although our finding did not meet statistical significance, this finding was similar to Schneider et al. who also demonstrated that LAS increased in subjects with MSR during a three month follow up in contrast to subjects with AFR [6]. Due to the low rates of post-conversion recurrent $\mathrm{AF}$, we acknowledge that further studies are needed in order to have the appropriate statistical power to address this issue. 
Table 4 Echocardiographic and strain variables of patients with maintained sinus rhythm (MSR) group as compared to the atrial fibrillation recurrence (AFR) group

\begin{tabular}{|c|c|c|c|c|c|c|}
\hline Echo variables & $\operatorname{MSR}(n=27)$ & & & AFR $(n=14)$ & & $P$ value \\
\hline LVIDd, mm & $49.6 \pm 2.6$ & & & $51.5 \pm 6.6$ & & 0.68 \\
\hline LVIDs, mm & $35.8 \pm 3.6$ & & & $35.2 \pm 6.6$ & & 0.84 \\
\hline $\mathrm{STd}, \mathrm{mm}$ & $10.4 \pm 0.8$ & & & $10.5 \pm 0.8$ & & 0.61 \\
\hline PWTd, mm & $10.1 \pm 0.8$ & & & $10.8 \pm 1.0$ & & 0.18 \\
\hline LVEF (\%) & $54.8 \pm 4.4$ & & & $52.5 \pm 7.0$ & & 0.72 \\
\hline $\mathrm{LAD}, \mathrm{mm}$ & $46.5 \pm 3.8$ & & & $44.7 \pm 9.4$ & & 0.95 \\
\hline Pre-CV LAVI, ml/M² & $34.5 \pm 5.0$ & & & $36.5 \pm 5.6$ & & 0.82 \\
\hline Post-CV LAVI, ml/M² & $35 \pm 5.6$ & & & $34.2 \pm 5.2$ & & 0.89 \\
\hline \multirow[t]{2}{*}{$\mathrm{E} / \mathrm{E}^{\prime}$} & $9.8 \pm 2.2$ & & & $12.5 \pm 2.6$ & & 0.07 \\
\hline & Pre-CV & Post-CV & $P$ value & Pre-CV & Post-CV & $P$ value \\
\hline$H R$ & $84.0(77.6-90.6)$ & $66.0(60.5-71.6)$ & $<0.01$ & $87.9(78.2-97.6)$ & $75.7(69.3-82.1)$ & 0.05 \\
\hline $\mathrm{LAVl}, \mathrm{ml} / \mathrm{M}^{2}$ & $34.5(29.4-39.8)$ & $35(29.2-40.9)$ & 0.87 & $36.5(30.9-42.1)$ & $34.2(29.0-39.4)$ & 0.19 \\
\hline $2 \mathrm{CLAS}, \%$ & $12.8(9.5-16.3)$ & $18.0(13.4-22.8)$ & 0.01 & $12.4(8.1-16.8)$ & $13.2(10.7-15.8)$ & 0.68 \\
\hline $4 C L A S, \%$ & $10.8(7.6-14.1)$ & $15.9(12.5-19.3)$ & $<0.01$ & $11.6(7.5-15.7)$ & $13.7(7.7-19.9)$ & 0.75 \\
\hline LAS, $\%$ & $11.8(9.1-14.6)$ & $17.0(13.2-20.8)$ & $<0.01$ & $12.0(8.3-15.7)$ & $13.5(9.5-17.6)$ & 0.38 \\
\hline 2CLASt & $0.92(0.63-1.20)$ & $1.42(-0.16-2.99)$ & 0.5 & $1.32(0.78-1.87)$ & $0.83(0.52-1.14)$ & 0.25 \\
\hline 4CLASt & $1.64(0.86-2.41)$ & $0.83(0.54-1.12)$ & 0.06 & $1.45(0.78-2.13)$ & $0.92(0.32-1.52)$ & 0.24 \\
\hline LASt & $1.28(0.81-1.76)$ & $1.12(0.25-1.99)$ & 0.92 & $1.39(0.81-1.97)$ & $0.88(0.43-1.33)$ & 0.22 \\
\hline
\end{tabular}

LVIDd - Left ventricular internal diameter at end- diastole, LVIDs - Left ventricular internal diameter at end- systole, STd - Interventricular septum thickness at enddiastole, PWTd - Left ventricular posterior wall thickness at end-diastole, LVEF - Left ventricular ejection fraction, LAD - Left atrial diameter, LAVI - Left atrial volume index, $\mathrm{E}=$ early filling velocity of transmitral Doppler flow, $\mathrm{E}^{\prime}=$ Average early diastolic velocity of medial and lateral mitral annulus, $\mathrm{HR}-\mathrm{Heart}$ rate, $2 \mathrm{CLAS}$ 2 chamber average peak systolic strain, 4CLAS - 4 chamber average peak systolic strain, LAS - Mean peak systolic strain of 2 C and $4 C, 2 C L A S t-2$ chamber left atrial stiffness, 4CLASt -4 chamber left atrial stiffness, LASt - Mean left atrial stiffness of $2 \mathrm{C}$ and $4 \mathrm{C}$.

The results of our study could be influenced by several factors. Even though we used a continuous event monitor for one month, we could have missed asymptomatic AF recurrences between month two to six of follow-up. The duration of persistent AF may have played a role in altering the predictive probability of strain for AF recurrence. In contrast to our study, which only included participants with persistent $\mathrm{AF}$, most of the studies that have shown that lower LAS is associated with higher recurrence rates have recruited subjects with both paroxysmal and persistent AF. Since Schneider et al. have reported lower strain values in subjects with persistent $\mathrm{AF}$ as compared

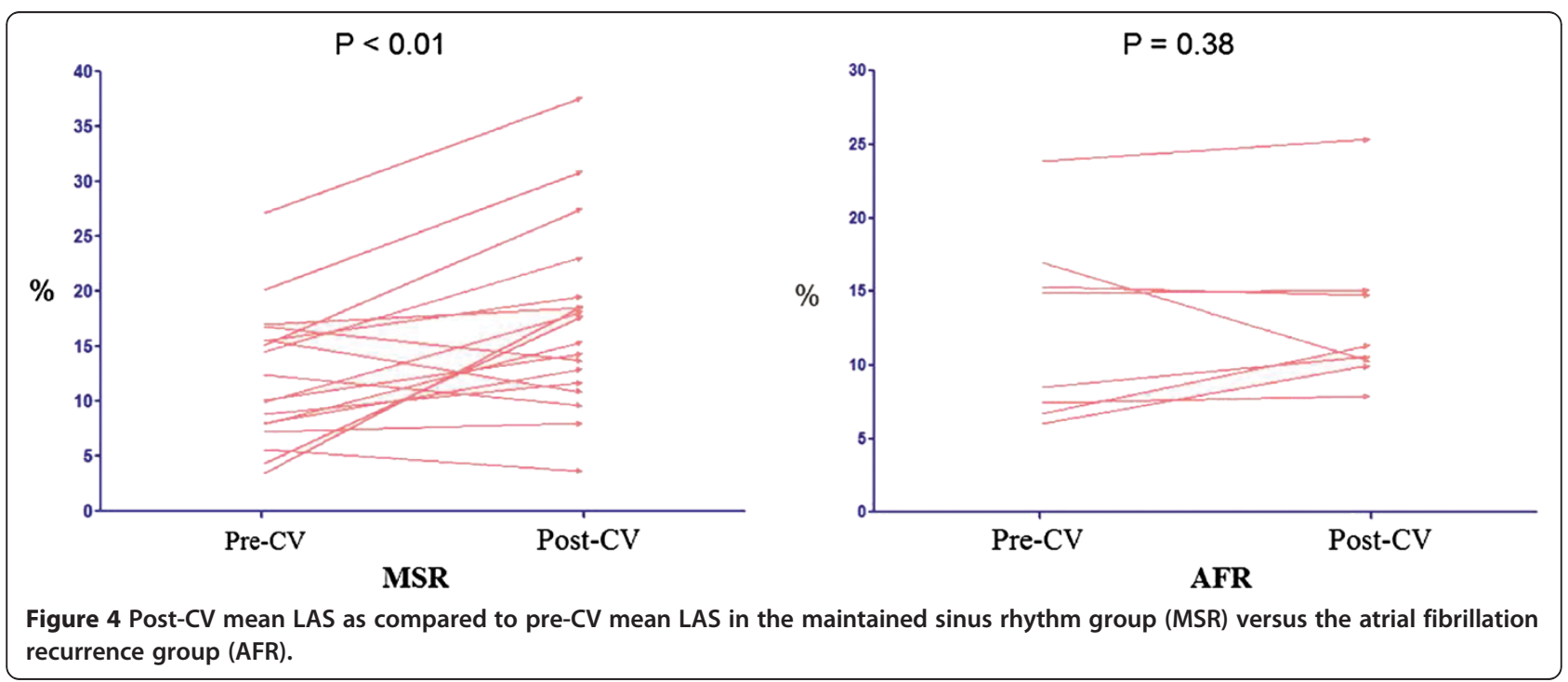


Table 5 Univariate and Multivariate predictors of maintenance of sinus rhythm in patients with atrial fibrillation (AF) after cardioversion

\begin{tabular}{lll}
\hline Parameter & \multicolumn{2}{l}{ Univariate regression } \\
\cline { 2 - 3 } & B co-efficient & P value \\
\hline Age & 2.3 & 0.53 \\
Sex & -0.2 & 0.14 \\
BMI & -2.4 & 0.35 \\
Pre-CV LAVI & 2.3 & 0.65 \\
Difference in LAVI & -2.8 & 0.44 \\
Pre-CV HR & -0.01 & 0.99 \\
Difference in HR & 7.3 & 0.27 \\
Pre-CV LAS & 0.06 & 0.98 \\
Difference in LAS & 3.1 & 0.09 \\
Pre-CV LASt & -0.2 & 0.55 \\
Difference in LASt & 0.5 & 0.59 \\
& Multivariate regression & \\
\cline { 2 - 3 } & $\mathbf{B}$ co-efficient & P value \\
\hline Sex & -0.2 & 0.32 \\
Difference in HR & 4.7 & 0.49 \\
Difference in LAS & 3.7 & 0.08 \\
\hline
\end{tabular}

to paroxysmal AF, it is possible that our exclusion of participants with paroxysmal AF may have influenced our findings [6]. Also, the platform utilized to analyze strain variables can possibly influence the magnitude of the strain values thus leading to differing results. Evaluation of LASt and LAS in a larger sample of participants with both paroxysmal and persistent AF is warranted to more fully evaluate the potential associations between LA strain measures and AF recurrences.

\section{Study limitations}

A long-term prospective study with repeated strain measurement over time would be ideal to assess the effects of reverse atrial modeling on strain and stiffness. Studies with larger sample size with subgroup analysis of paroxysmal and persistent AF would be beneficial in further evaluating role of strain as predictive markers for AF recurrence.

\section{Clinical implication}

Recent studies suggest LA strain as a predictor of stroke risk and cardiovascular outcomes in patients with $\mathrm{AF}$ $[29,30]$. A better understanding of atrial physiology might potentially permit targeted strategies to prevent $\mathrm{AF}$ recurrence, thereby decreasing the risk of major adverse cardiovascular outcomes. While baseline atrial strain does not appear to be a predictor of the maintenance of sinus rhythm, our data do suggest the hypothesis that improvement in strain following $\mathrm{CV}$ is a favorable prognostic sign.

\section{Conclusion}

We observed that LAS and LASt differed between participants with and without AF, irrespective of the rhythm at the time of echocardiographic assessment; to our knowledge, ours is the first study analyzing left atrial stiffness index before and after cardioversion. Unlike prior studies, we did not find LAS or LASt at baseline to be an independent predictor of AF recurrence. However, our results suggest that change in LAS after CV may be a useful predictor of recurrent arrhythmia. Further long term follow up studies are required to establish the role of this stiffness index utilizing non-invasive surrogate markers of left atrial filling pressure.

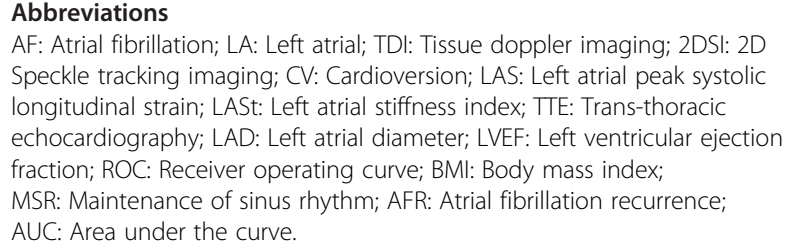

\section{Competing interests}

The author declares that he has no competing interests

\section{Authors' contributions}

AYS - Concept/design, Data analysis/interpretation, Drafting article, Critical revision of article, Approval of article, Statistics, Data collection, Other. AM Drafting article, Critical revision of article, Approval of article, Data collection UAK - Critical revision of article, Approval of article, Data collection. GPA Concept/design, Data analysis/interpretation, Drafting article, Critical revision of article, Approval of article, Statistics, Data collection, Other. JCH - Critical revision of article, Approval of article, Statistics, Data collection, Other. JLK Approval of article, Data collection, Other. DAT - Critical revision of article, Approval of article, Statistics, Other. EM - Critical revision of article, Approval of article, Statistics. DDM - Concept/design, Data analysis/interpretation, Drafting article, Critical revision of article, Approval of article, Statistics, Funding secured by, Data collection, Other. All authors read and approved the final manuscript.

\section{Funding}

This study was funded by the Cardiology Division, University of Massachusetts Medical School, by the National Heart, Lung and Blood Institute (1U01HL105268-01) and by KL2RR031981.

\section{Financial disclosures}

AYS - None; AM - None; UAK - None; GPA - None; JCH - consulting contract with Philips Healthcare; JLK - None; DAT - None; EM - None; DDM - Research funding support: Biotronik, Inc. and Philips Healthcare, Inc. All authors contributed equally to this manuscript.

\section{Author details}

'Department of Internal Medicine, University of Massachusetts Medical School, Worcester, USA. ${ }^{2}$ Division of Cardiovascular Medicine, University of Massachusetts Medical School, Worcester, USA. ${ }^{3}$ Sanford-Brown College of Boston, Boston, USA. ${ }^{4}$ Department of Quantitative Health Sciences, University of Massachusetts Medical School, Worcester, USA. ${ }^{5}$ Department of Medicine, Cardiology Division, Electrophysiology Section, University of Massachusetts Medical Center, 55 Lake Avenue North, Worcester, MA 01655, USA.

Received: 23 October 2012 Accepted: 29 November 2012

Published: 3 December 2012 


\section{References}

1. Cho GY, Jo SH, Kim MK, Kim HS, Park WJ, Choi YJ, Hong KS, Oh DJ, Rhim CY: Left atrial dyssynchrony assessed by strain imaging in predicting future development of atrial fibrillation in patients with heart failure. Int J Cardiol 2009, 134(3):336-341.

2. Wang T, Wang M, Fung JW, Yip GW, Zhang Y, Ho PP, Tse DM, Yu CM, Sanderson JE: Atrial strain rate echocardiography can predict success or failure of CV for atrial fibrillation: a combined transthoracic tissue Doppler and transoesophageal imaging study. Int J Cardio/ 2007 114(2):202-209.

3. Di Salvo G, Caso P, Lo Piccolo R, Fusco A, Martiniello AR, Russo MG, D'Onofrio A, Severino S, Calabro P, Pacileo G, Mininni N, Calabro R: Atrial myocardial deformation properties predict maintenance of sinus rhythm after external CV of recent-onset lone atrial fibrillation: a color Doppler myocardial imaging and transthoracic and transesophageal echocardiographic study. Circulation 2005, 112(3):387-395.

4. Tsai WC, Lee CH, Lin CC, Liu YW, Huang YY, Li WT, Chen JY, Lin L: Association of Left Atrial Strain and Strain Rate Assessed by Speckle Tracking Echocardiography with Paroxysmal Atrial Fibrillation. Echocardiography 2009, 26(10):1188-1194.

5. Wang Z, Tan H, Zhong M, Jiang G, Zhang Y, Zhang W: Strain rate imaging for noninvasive functional quantification of the left atrium in hypertensive patients with paroxysmal atrial fibrillation. Cardiology 2008, 109(1):15-24.

6. Schneider C, Malisius R, Krause K, Lampe F, Bahlmann E, Boczor S, Antz M, Ernst S, Kuck KH: Strain rate imaging for functional quantification of the left atrium: atrial deformation predicts the maintenance of sinus rhythm after catheter ablation of atrial fibrillation. Eur Heart J 2008, 29(11):1397-1409.

7. Thomas L, McKay T, Byth K, Marwick TH: Abnormalities of left atrial function after CV: an atrial strain rate study. Heart 2007, 93(1):89-95.

8. McManus DD, Shaikh AY, Abhishek F, Vasan RS: Atrial fibrillation and heart failure parallels: lessons for atrial fibrillation prevention. Crit Pathw Cardiol 2011, 10(1):46-51.

9. Hwang HJ, Choi EY, Rhee SJ, Joung B, Lee BH, Lee SH, Kim J, Lee MH, Jang $Y$, Chung N, Kim SS: Left atrial strain as predictor of successful outcomes in catheter ablation for atrial fibrillation: a two-dimensional myocardial imaging study. J Interv Card Electrophysiol 2009, 26(2):127-132.

10. Thijssen VL, Ausma J, Borgers M: Structural remodeling during chronic atrial fibrillation: act of programmed cell survival. Cardiovasc Res 2001, 52(1):14-24.

11. Sitges M, Teijeira VA, Scalise A, Vidal B, Tamborero D, Collvinent B, Rivera S, Molina I, Azqueta M, Pare C, Brugada J, Mont L: Is there an anatomical substrate for idiopathic paroxysmal atrial fibrillation? A case-control echocardiographic study. Europace 2007, 9(5):294-298.

12. Olshansky B, Heller EN, Mitchell LB, Chandler M, Slater W, Green M, Brodsky M, Barrell P, Greene HL: Are transthoracic echocardiographic parameters associated with atrial fibrillation recurrence or stroke? Results from the Atrial Fibrillation Follow-Up Investigation of Rhythm Management (AFFIRM) study. J Am Coll Cardiol 2005, 45(12):2026-2033.

13. Dittrich HC, Pearce LA, Asinger RW, McBride R, Webel R, Zabalgoitia M, Pennock GD, Safford RE, Rothbart RM, Halperin JL, Hart RG: Left atrial diameter in nonvalvular atrial fibrillation: An echocardiographic study. Stroke Prevention in Atrial Fibrillation Investigators. Am Heart J 1999, 137(3):494-499.

14. Kizer JR, Bella JN, Palmieri V, Liu JE, Best LG, Lee ET, Roman MJ, Devereux RB: Left atrial diameter as an independent predictor of first clinical cardiovascular events in middle-aged and elderly adults: the Strong Heart Study (SHS). Am Heart J 2006, 151(2):412-418.

15. Vianna-Pinton R, Moreno CA, Baxter CM, Lee KS, Tsang TS, Appleton CP: Two-dimensional speckle-tracking echocardiography of the left atrium: feasibility and regional contraction and relaxation differences in normal subjects. J Am Soc Echocardiogr 2009, 22(3):299-305.

16. Sanfilippo AJ, Abascal VM, Sheehan M, Oertel LB, Harrigan P, Hughes RA, Weyman AE: Atrial enlargement as a consequence of atrial fibrillation. A prospective echocardiographic study. Circulation 1990, 82(3):792-797.

17. Leung DY, Boyd A, Ng AA, Chi C, Thomas L: Echocardiographic evaluation of left atrial size and function: current understanding, pathophysiologic correlates, and prognostic implications. Am Heart J 2008, 156(6):1056-1064.

18. Inaba Y, Yuda S, Kobayashi N, Hashimoto A, Uno K, Nakata T, Tsuchihashi K, Miura T, Ura N, Shimamoto $K$ : Strain rate imaging for noninvasive functional quantification of the left atrium: comparative studies in controls and patients with atrial fibrillation. J Am Soc Echocardiogr 2005, 18(7):729-736.
19. Zhang Q, Yip GW, Yu CM: Approaching regional left atrial function by tissue Doppler velocity and strain imaging. Europace 2008, 10(Suppl 3):iii62-iii69.

20. Mirza M, Caracciolo G, Khan U, Mori N, Saha SK, Srivathsan K, Altemose G, Scott L, Sengupta $P$, Jahangir A: Left atrial reservoir function predicts atrial fibrillation recurrence after catheter ablation: a two-dimensional speckle strain study. J Interv Card Electrophysiol 2011, 31(3):197-206.

21. Machino-Ohtsuka T, Seo Y, Tada H, Ishizu T, Machino T, Yamasaki H, Igarashi M, Xu D, Sekiguchi Y, Aonuma K: Left atrial stiffness relates to left ventricular diastolic dysfunction and recurrence after pulmonary vein isolation for atrial fibrillation. J Cardiovasc Electrophysio/ 2011, 22(9):999-1006.

22. Hammerstingl C, Schwekendiek M, Momcilovic D, Schueler R, Sinning JM, Schrickel JW, Mittmann-Braun E, Nickenig G, Lickfett L: Left atrial deformation imaging with ultrasound based two-dimensional speckle-tracking predicts the rate of recurrence of paroxysmal and persistent atrial fibrillation after successful ablation procedures. J Cardiovasc Electrophysiol 2011, doi:10.1111/ j.1540-8167.2011.02177.x. Epub ahead of print.

23. Fuster V, Ryden LE, Asinger RW, Cannom DS, Crijns HJ, Frye RL, Halperin JL, Kay GN, Klein WW, Lévy S, McNamara RL, Prystowsky EN, Wann LS, Wyse DG, Gibbons RJ, Antman EM, Alpert JS, Faxon DP, Fuster V, Gregoratos G, Hiratzka LF, Jacobs AK, Russell RO, Smith SC Jr, Klein WW, Alonso-Garcia A, Blomström-Lundqvist C, de Backer G, Flather M, Hradec J, et al: ACC/AHA/ ESC guidelines for the management of patients with atrial fibrillation: executive summary: a report of the American College of Cardiology/ American Heart Association Task Force on Practice Guidelines and the European Society of Cardiology Committee for Practice Guidelines and Policy Conferences (Committee to Develop Guidelines for the Management of Patients With Atrial Fibrillation). Circulation 2001, 104:2118-2150.

24. Lang RM, Bierig M, Devereux RB, Flachskampf FA, Foster E, Pellikka PA, Picard MH, Roman MJ, Seward J, Shanewise JS, Solomon SD, Spencer KT, Sutton MS, Stewart WJ, Chamber Quantification Writing Group; American Society of Echocardiography's Guidelines and Standards Committee; European Association of Echocardiography: Recommendations for chamber quantification: a report from the American Society of Echocardiography's Guidelines and Standards Committee and the Chamber Quantification Writing Group, developed in conjunction with the European Association of Echocardiography, a branch of the European Society of Cardiology. J Am Soc Echocardiogr 2005, 18(12):1440-1463.

25. Nagueh SF, Middleton KJ, Kopelen HA, Zoghbi WA, Quiñones MA: Doppler tissue imaging: a noninvasive technique for evaluation of left ventricular relaxation and estimation of filling pressures. J Am Coll Cardio/ 1997, 30(6):1527-1533.

26. Kuppahally SS, Akoum N, Burgon NS, Badger TJ, Kholmovski EG, Vijayakumar S, Rao SN, Blauer J, Fish EN, Dibella EV, Macleod RS, McGann C, Litwin SE, Marrouche NF: Left atrial strain and strain rate in patients with paroxysmal and persistent atrial fibrillation: relationship to left atrial structural remodeling detected by delayed-enhancement MRI. Circ Cardiovasc Imaging 2010, 3(3):231-239.

27. Thomas L, Boyd A, Thomas SP, Schiller NB, Ross DL: Atrial structural remodelling and restoration of atrial contraction after linear ablation for atrial fibrillation. Eur Heart J 2003, 24(21):1942-1951.

28. Nishino M, Hoshida S, Tanouchi J, Ito T, Kato J, Iwai K, Tanahashi H, Hori M, Yamada Y, Kamada T: Time to recover from atrial hormonal, mechanical, and electrical dysfunction after successful electrical CV of persistent atrial fibrillation. Am J Cardiol 2000, 85(12):1451-1454.

29. Saha SK, Anderson PL, Caracciolo G, Kiotsekoglou A, Wilansky S, Govind S, Mori N, Sengupta PP: Global left atrial strain correlates with CHADS2 risk score in patients with atrial fibrillation. J Am Soc Echocardiogr 2011, 24(5):506-512.

30. Azemi T, Rabdiya VM, Ayirala SR, McCullough LD, Silverman DI: Left atrial strain is reduced in patients with atrial fibrillation, stroke or TIA, and low risk CHADS(2) scores. J Am Soc Echocardiogr 2012, doi:pii:S0894-7317(12) 00715-8. 10.1016/j.echo.2012.09.004. Epub ahead of print.

\section{doi:10.1186/1476-7120-10-48}

Cite this article as: Shaikh et al: Speckle echocardiographic left atrial strain and stiffness index as predictors of maintenance of sinus rhythm after cardioversion for atrial fibrillation: a prospective study.

Cardiovascular Ultrasound 2012 10:48. 